\title{
Ability of GHTD-amide and analogs to enhance insulin activity through zinc chelation and dispersal of insulin oligomers
}

\author{
Sarah G. Paule ${ }^{a}$, Biljana Nikolovski ${ }^{a}$, Justin Ludeman ${ }^{a}$, Robyn E. Gray ${ }^{a}$, Leone Spiccia ${ }^{b}$, \\ Paul Z. Zimmet ${ }^{\mathrm{a}, \mathrm{c}}$, Mark A. Myers ${ }^{\mathrm{a}, \mathrm{d}, *}$ \\ ${ }^{a}$ Department of Biochemistry and Molecular Biology, Monash University, Clayton, Victoria, Australia \\ ${ }^{\mathrm{b}}$ School of Chemistry, Monash University, Clayton, Victoria, Australia \\ ${ }^{c}$ Baker IDI Heart and Diabetes Research Institute, Caulfield, Victoria, Australia \\ ${ }^{\mathrm{d}}$ School of Science and Engineering, University of Ballarat, Ballarat, Victoria, Australia
}

\section{A R T I C L E I N F O}

\section{Article history:}

Received 28 January 2009

Received in revised form 25 February 2009

Accepted 26 February 2009

Available online $\mathrm{xxx}$

\section{Keywords:}

Zinc

Chelation

Peptide

Insulin

Type 2 diabetes

C-peptide

Zucker rat

Insulin hexamers

\section{Introduction}

In the 1970s, during a search for naturally occurring molecules with glucose lowering activity, a partially purified peptide preparation was isolated from human urine $[17,18]$. The active constituent has been identified as a tetrapeptide with the amino acid sequence Gly His Thr Asp amidated at the $C$ terminus (GHTD amide) [19]. The mechanism of action of this peptide remains unknown.

\footnotetext{
* Corresponding author at: School of Science and Engineering, University of Ballarat, University Drive, Mt. Helen, Victoria, 3353, Australia. Tel.: +61 353279291 ; fax: +61 353279240 .

E-mail address: m.myers@ballarat.edu.au (M.A. Myers). Abbreviations: AUC, area under the curve; ITT, insulin tolerance test; ISF402, the tetrapeptide Val-His-Thr-Asp-amide.
}

Insulin is an allosteric protein that forms hexameric complexes with zinc ions, which strongly influence the stability and dynamic properties of the complex [20,21]. The formation of these hexamers likely plays critically important roles in the synthesis, assembly and storage of insulin [23,2,3]. Zinc stabilized hexamers of insulin must disperse to monomeric form in order to bind to the insulin receptor to initiate the cascade of protein phosphorylation that culminates in cellular glucose uptake and storage [8].

Histidine containing peptides like GHTD amide generally bind zinc ions and some zinc binding molecules can disperse zinc stabilized insulin hexamers to monomers [24]. This raises the question of whether dispersal of zinc insulin hexamers plays a role in insulin potentiation by GHTD amide. The aim of this study was to characterize the binding of zinc ions by GHTD amide, an analog called ISF402 (VHTD amide) and the tripeptide HTD amide, test their ability to disperse hexameric insulin and establish the 
contribution of this activity to enhancement of insulin activity in vivo.

\section{Research design and methods}

\subsection{Peptides}

The peptides GHTD amide and ISF402 (VHTD amide) used for in vivo experiments were synthesized by standard solid phase Fmoc chemistry (Mimotopes, Clayton, Australia) and isolated as TFA salts. The peptide VHTD amide (acetate salt) used for in vitro studies was synthesized by liquid phase methods (PolyPeptide Laboratories, CA, USA). HTD amide and the tri /tetrapeptide analogs Ac HTD amide, VHT amide, Ac VHTD amide, VHTD OH, VVTD amide, VHTN amide, VHAD amide, DTHV amide, GHTD amide, ARSE amide, GHSE amide were all synthesized by solid phase Fmoc chemistry as TFA salts (GL Biochem, Shanghai, China).

Bovine hexameric zinc insulin and recombinant (rec) human insulin were purchased from Sigma (St Louis, MO). Pharmaceutical grade human insulin (Humalin) was sourced from Eli Lilly (NSW, Australia).

HTD amide used for potentiometric titration was lyophilized three times in a $2: 1$ solution of $0.05 \mathrm{~N} \mathrm{HCl}_{(\mathrm{aq})}$ and acetonitrile to remove TFA [1]. HPLC standard curves were generated for VHTD amide, HTD amide, and VVTD amide from batches of known peptide content using a Shimadzu 10AT VP System equipped with a PDA detector (214 nm) and a Phenomenex Luna(2) C 18 column, $250 \mathrm{~mm} \times 4.6 \mathrm{~mm}$. All peptide samples were eluted with a $20 \mathrm{~min}$ gradient of $025 \%$ acetonitrile; both water and acetonitrile mobile phases contained $0.1 \%(\mathrm{v} / \mathrm{v})$ TFA. The concentrations of stock solutions of other analogs were determined from the standard curves of HTD amide, VHTD amide, or VVTD amide (whichever was most chemically similar) and corrected by a ratio of the theoretical molar extinction coefficients for the standard peptide and the peptide of unknown concentration [14]. All measurements were corrected for peptide content.

\subsection{Ion Trap Electro Spray Ionization Mass Spectrometry}

Mass spectrometry was performed using a Bruker 1200 series Ion Trap Electro Spray Mass Spectrometer, and all spectra were recorded in the positive ion mode with voltages less than $30 \mathrm{~V}$ to minimize destruction of peptide $\mathrm{Zn}^{2+}$ ion adducts. For all experiments, a $5 \mathrm{mM}$ ammonium acetate buffer system was used and adjusted to $\mathrm{pH}$ 7.0. Peptide and zinc(II) nitrate stocks (prepared using $\mathrm{Zn}\left(\mathrm{NO}_{3}\right)_{2} 6 \mathrm{H}_{2} \mathrm{O}$ ) were also adjusted to $\mathrm{pH}$ 7.0. Samples were measured within $48 \mathrm{~h}$ of preparation and no difference in spectral patterns was observed between samples measured $1 \mathrm{~h}$ or 1 day after preparation. Degassed $18.2 \mathrm{M} \Omega$ water was the most satisfactory solvent for these analyses as it yielded the cleanest spectra.

\subsection{Circular dichroism}

All Circular dichroism (CD) measurements were performed at $25^{\circ} \mathrm{C}$ on Jasco J 810 or J 815 spectropolarimeters equipped with a PFD 423S/L Peltier type temperature controller. For far UV peptide $\mathrm{Zn}^{2+}$ binding experiments, the instrument bandwidth was set at $1.0 \mathrm{~nm}$ and scans across $190250 \mathrm{~nm}$ were averaged across 5 accumulations at $50 \mathrm{~nm} / \mathrm{min}$. For near UV experiments to study the effects of $\mathrm{Zn}^{2+}$ binding peptides on insulin aggregation, the instrument bandwidth was set at $2.0 \mathrm{~nm}$ and scans across the $250300 \mathrm{~nm}$ range were averaged for 5 accumulations at $50 \mathrm{~nm} /$ min. The diluents in all CD experiments was freshly prepared, filtered and degassed $20 \mathrm{mM}$ Tris $\mathrm{HCl}, \mathrm{pH}$ 7.0. All spectra were corrected for background.

\subsection{Peptide far UV CD}

All peptide analogs were screened for $\mathrm{Zn}^{2+}$ binding in the far UV (190 $250 \mathrm{~nm}$ ) using a $600 \mu \mathrm{l}, 2 \mathrm{~mm}$ path length quartz cuvette. Each peptide $(100 \mu \mathrm{M})$ was scanned in the absence and presence

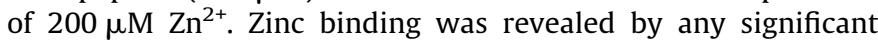
increase in the negative ellipticity at $220 \mathrm{~nm}$ upon addition of $\mathrm{Zn}^{2+}$. Such changes in ellipticity were assumed to reflect peptide conformational constraint induced by $\mathrm{Zn}^{2+}$ binding. Furthermore, changes in ellipticity suggested a saturable binding mode that would enable comparison of the relative affinities of different peptide analogs for $\mathrm{Zn}^{2+}$. Measurements were performed in ultrapure water at a $\mathrm{pH}$ of 7.4.

The peptides GHTD amide, VHTD amide and HTD amide were selected for $\mathrm{Zn}^{2+}$ titration analysis in the far UV region (190 $250 \mathrm{~nm}$ ) using a $3.5 \mathrm{ml}, 10 \mathrm{~mm}$ path length cuvette. Assuming 1:1 binding, the concentration of bound zinc $\left(\left[\mathrm{Zn}^{2+}\right]_{\mathrm{B}}\right)$ was determined as a fraction of the peptide concentration (constant) multiplied by the normalized change in $\mathrm{CD}$ for each titration sample. Free zinc concentration $\left(\left[\mathrm{Zn}^{2+}\right]_{\mathrm{F}}\right)$ was then calculated by subtracting $\left[\mathrm{Zn}^{2+}\right]_{\mathrm{B}}$ from $\left[\mathrm{Zn}^{2+}\right]_{\mathrm{T}}$. Non linear regression analysis (single site hyperbolic binding) was performed on plots of $\left[\mathrm{Zn}^{2+}\right]_{\mathrm{B}}$ vs $\left[\mathrm{Zn}^{2+}\right]_{\mathrm{F}}$ to yield estimates of $K_{\mathrm{D}}$, according to Eq. (1):

$Y \quad B_{\mathrm{MAX}} \frac{X}{K_{\mathrm{D}}+X}$

where $B_{\text {MAX }}$ represents maximal binding and $K_{\mathrm{D}}$ is the ligand concentration at which half maximal binding is achieved. All data analysis was performed using GraphPad Prism Software. Experi ments were refined to ensure consecutive 2 fold dilutions of the peptide gave very similar values for $K_{\mathrm{D}}$. This entailed titrating the lowest peptide concentrations (between 10 and $100 \mu \mathrm{M}$ ) to eliminate derivation of erroneously high $K_{\mathrm{D}}$ values. Overestimation of $K_{\mathrm{D}}$ values was apparent at peptide concentrations greater than $100 \mu \mathrm{M}$ for VHTD amide/GHTD amide and $50 \mu \mathrm{M}$ for HTD amide. Similarly, lower peptide concentrations enabled higher zinc ratios to be employed, without compromising spectral quality. All measurements were performed at $\mathrm{pH}$ 7.4.

\subsection{Insulin far and near $U V C D$}

Humalin (2Zn insulin) was assayed for aggregation using far UV $(190250 \mathrm{~nm})$ and near UV (250 $300 \mathrm{~nm})$ CD as reported pre viously for studies of bovine and human insulin [12,5,15] enabling the effects of zinc binding peptides on insulin hexamer dispersal to be studied. All experiments were performed using a $1 \mathrm{~mm}$ path length quartz cuvette due to the high protein concentrations employed. Samples were incubated for $10 \mathrm{~min}$ prior to reading to enable re equilibration of insulin aggregates upon the addition of zinc binding peptide. Humalin insulin $(100 \mu \mathrm{M})$ was titrated with HTD amide at ratios of $1: 1$ and 1:2 insulin:HTD. Comparison of ellipticity at $275 \mathrm{~nm}$ between either insulin alone and HTD titrated samples revealed changes in the insulin aggregation state.

\subsection{Potentiometry}

Potentiometric titration of HTD alone and several ratios of HTD: $Z^{2+}(1: 1,2: 1,4: 1$ and $8: 1)$ was performed to verify the apparent $1: 1$ and $1: 2 \mathrm{HTD}: \mathrm{Zn}^{2+}$ binding stoichiometry detected using Ion Trap ESI MS. Titrations were performed using a Metrohm 808 Titrando equipped with a 801 stirrer and $10 \mathrm{ml}$ reaction vessel; data was collected using Tiamo software v.1.0. Standardized $\mathrm{KOH}$ titrant $(0.84 \mathrm{M}), \mathrm{KNO}_{3}(1.0 \mathrm{M})$ and all $\mathrm{HTD}$ amide and zinc nitrate stock solutions were freshly prepared each day using degassed $18.2 \mathrm{M} \Omega$ resistivity water. The $\mathrm{KNO}_{3}$ solution was used to adjust the ionic strength of all samples to $0.1 \mathrm{M}$ prior to 
titration analysis. HTD was used at a final concentration of $1 \mathrm{mM}$ in all samples. Triplicate data sets were generated for HTD alone and each HTD: $\mathrm{Zn}^{2+}$ ratio. All titrations were performed under a constant $\mathrm{N}_{2}$ (g) stream to prevent $\mathrm{CO}_{2}$ ingress and formation of bicarbonate ions in reaction solution.

\subsection{Insulin hexamer dispersal by size exclusion chromatography}

Size exclusion chromatography was used to study the effect of GHTD amide on hexameric insulin. Recombinant human insulin solution was diluted to $2 \mathrm{mg} / \mathrm{ml}$ with $10 \mathrm{mM}$ Tris $\mathrm{pH} 7.4$ and dialyzed against $10 \mathrm{mM}$ Tris $\mathrm{pH}$ 7.4. This was performed to remove HEPES from the solution, which absorbs strongly at $214 \mathrm{~nm}$ and co elutes with GHTD amide. An insulin stock solution at $1.5 \mathrm{mg} / \mathrm{ml}$ was then prepared by the addition of phenol to $4 \mathrm{mM}, \mathrm{NaCl}$ to $140 \mathrm{mM}$ and $\mathrm{ZnCl}_{2}$ to $100 \mu \mathrm{M}$. Prior to chromatography the stock insulin was mixed with either water or test peptide to give a final concentration of $1 \mathrm{mg} / \mathrm{ml}$ each of insulin and test peptide where applicable, and $10 \mathrm{mM}$ Tris $\mathrm{pH} 7.4,140 \mathrm{mM} \mathrm{NaCl}$ and $100 \mathrm{mM}$ $\mathrm{ZnCl}_{2}$. The insulin and peptide mixtures were incubated at room temperature $\left(22 \pm 3^{\circ} \mathrm{C}\right)$ for $1 \mathrm{~h}$ and then subjected to size exclusion chromatography using a $1 \mathrm{~cm} \times 30 \mathrm{~cm}$ Superdex 75 HR 10/30 column at a flow rate of $0.1 \mathrm{ml} \mathrm{min}{ }^{1}$ with an eluent comprising Tris buffered isotonic saline (140 mM NaCl, $10 \mathrm{mM}$ Tris/ $\mathrm{HCl} \mathrm{pH}$ 7.4, $60 \mu \mathrm{M} \mathrm{ZnCl}_{2}$ ). UV absorption of the eluate was measured at 214 and $276 \mathrm{~nm}$, and $0.5 \mathrm{ml}$ fractions were collected for protein determination. Protein size standards aprotinin (6 kDa) and carbonic anhydrase (29 kDa) run under the same conditions eluted at 18.85 and $14.75 \mathrm{ml}$, respectively. A non zinc chelating peptide (NCP) with the sequence Ala Arg Ser Glu amide was used as a negative control.

The gel matrix, which has a fractionation range of 3000 $70000 \mathrm{Da}$, and the sample volume loaded were chosen to ensure that the two peptides remained in contact within the gel matrix thereby allowing interaction to occur between the two during the separation process. The concentration of insulin was maintained at $1 \mathrm{mg} / \mathrm{ml}$ at $\mathrm{pH} 7.4$ in the presence of $2 \mathrm{Zn}^{2+} /$ hexamer since it has been shown that at this concentration insulin exists predomi nantly as $\mathrm{Zn}^{2+}$ dependent hexamers. Under these conditions the addition of excess EDTA to the insulin solution resulted in the appearance of a large shoulder on the insulin peak corresponding to dimeric insulin (data not shown).

\subsection{Animals}

All experiments were performed according to Monash Uni versity Animal Care and Ethics Committee guidelines and approved by the Monash University Animal Ethics Committee. Zucker $f a / f a(Z D F / A s m u)$ rats were from Monash Animal Services (Monash University, Victoria, Australia). Sprague Dawley (Crj:CD(SD)IGS) rats were from the Animal Resource Center (Canning Vale, Western Australia). ZDF rats were used at 1420 weeks of age and on average weighed $370 \pm 24 \mathrm{~g}$ for females and $430 \pm 50 \mathrm{~g}$ for males. The average weight of the male Sprague Dawley rats was $464 \pm 50 \mathrm{~g}$. Rats were housed in an environmentally controlled room at $22{ }^{\circ} \mathrm{C}$ and allowed to acclimatize for 7 days. Rats were fed normal chow and water ad libitum.

Prior to the experiment, rats were fasted overnight $(16 \mathrm{~h})$. Sodium pentobarbitone (Nembutal, Phone Merieux, QLD, Austra lia) was injected intraperitoneally at $35 \mathrm{mg} / \mathrm{kg}$ and blood glucose was monitored using Medisense glucometers (Abbott Laboratories, Abbott Park, IL). Rats were placed on heat pads while under pentobarbitone anesthesia to prevent hypothermia. Under these conditions glucose homeostasis is comparable to unanesthetized animals [15]. GHTD amide and ISF402 $(1.5 \mathrm{mg} / \mathrm{kg})$ and insulin were dissolved in sterile $0.9 \%$ saline and injected through the femoral vein at the doses indicated. A dose of $1.5 \mathrm{mg} / \mathrm{kg}$ was chosen as the optimal dose based on dose ranging studies in Zucker rats (data not shown). For co injection, peptide was mixed with hexameric zinc insulin (Sigma, St Louis, MO) just prior to injection. $1 \mathrm{U} / \mathrm{kg}$ of insulin was intravenously administered into Zucker rats and $0.5 \mathrm{U} / \mathrm{kg}$ of insulin in Sprague Dawley rats. Intravenous rather than subcutaneous injection was chosen in order to test the effect of the peptides on insulin in solution rather than on the rate of systemic absorption from a subcutaneous injection site [5]. Soluble insulin concentrations in the injection solutions were not influenced by the presence of peptide as shown by optical density measurement at 260 and $280 \mathrm{~nm}$ (data not shown). Whole blood was collected from the tail vein and blood glucose measured immediately. Serum was separated using capiject serum separator tubes (Terumo, Elkton, MD) and stored at $80^{\circ} \mathrm{C}$ for later analysis of insulin and $C$ peptide using rat insulin and $C$ peptide radio immunoassay kits (Linco Research Inc., St. Charles, MO).

\subsection{Statistical analysis}

Where appropriate data were assessed by ANOVA and Bonferroni post hoc comparisons using GraphPad Prism software. Area under the curve (AUC) was calculated by the trapezoidal method and analyzed by Student's $t$ test.

\section{Results}

\section{1. $\mathrm{Zn}^{2+}$ binding by HTD amide peptides}

Mass Spectrometry and circular dichroism were used to analyze $\mathrm{Zn}^{2+}$ binding by GHTD amide, ISF402, HTD amide and various analogs. The tripeptide HTD amide was included because the amino terminal Gly has been found to be cleaved from GHTD amide in biological fluids (data not shown) hence the tripeptide may have biological relevance. Binding to zinc can induce structure into short peptides that would otherwise be expected to behave randomly in solution so the effect of zinc ions on the secondary structure of the peptides was examined using far UV circular dichroism (Fig. 1A F). The CD profile of ISF402 in the absence of zinc was typical of random coil with a pronounced negative peak at $198 \mathrm{~nm}$ (Fig. 1A). Upon addition of $\mathrm{Zn}^{2+}$ the negative peak displayed a slight shift to $200 \mathrm{~nm}$ and a second negative peak appeared at $220 \mathrm{~nm}$. Similar results were seen for GHTD amide (data not shown) and HTD amide (Fig. 1B). No change in CD profile was observed for ARSE amide, which lacks histidine, and the $\mathrm{N}$ terminally acetylated peptides Ac HTD amide and Ac VHTD amide showed only small changes in $\mathrm{CD}$ profile upon the addition of $\mathrm{Zn}^{2+}$ (Fig. 1B and D). Similar data for a range of analogs is summarized in Table 1 . The peptides that formed the most stable complexes with $\mathrm{Zn}^{2+}$ were those containing a Histidine residue close to or at the $\mathrm{N}$ terminus and with a free $\alpha$ amino group. The peptide with the sequence of ISF402 reversed, DTHV amide, bound $\mathrm{Zn}^{2+}$ very poorly suggesting that separation of the Histidine residue from the $\mathrm{N}$ terminal $\alpha$ amino group also results in poorer binding. Ion Trap Electro Spray Ionization Mass Spectrometry was used to detect the presence of peptide $\mathrm{Zn}^{2+}$ complexes and provide an indication of stoichiometry (Fig. $1 \mathrm{G}$ and $\mathrm{H}$ and Table 1). All histidine containing $\mathrm{Zn}^{2+}$ binding peptides bound $\mathrm{Zn}^{2+}$ in a $1: 1$ to ratio and, of these peptides, those containing aspartic acid also formed complexes with a $2: 1$ peptide: $: \mathrm{Z}^{2+}$ stoichiometry (Table 1 ). of all the peptides tested, the tripeptide HTD amide alone displayed $1: 1$ and $2: 1 \mathrm{HTD}: \mathrm{Zn}^{2+}$ adducts that were more predominant than the remaining monomeric peptide $(\mathrm{m} /$ $z=371.01$ ); illustrated by the clusters at $m / z=432.95$ and 803.12, respectively (Fig. $1 \mathrm{H}$ ). HTD amide also demonstrated a propensity to form soluble multimers ranging in size from monomer to tetramer, but these multimers were not detectable 
(a)

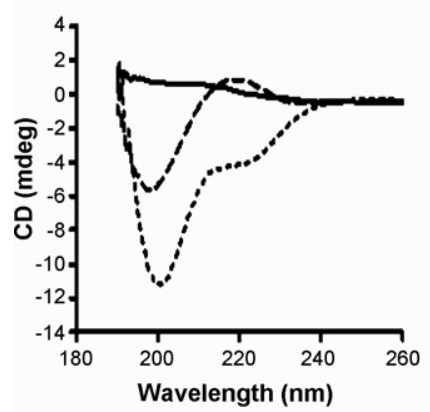

(b) Ac-VHTD-amide

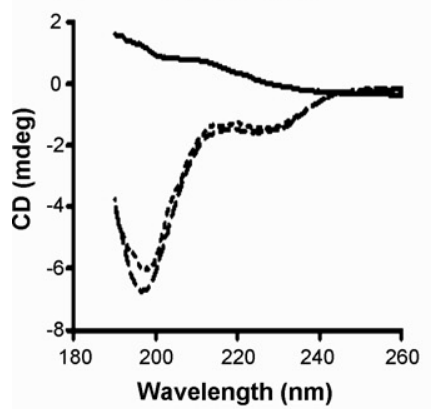

(c)

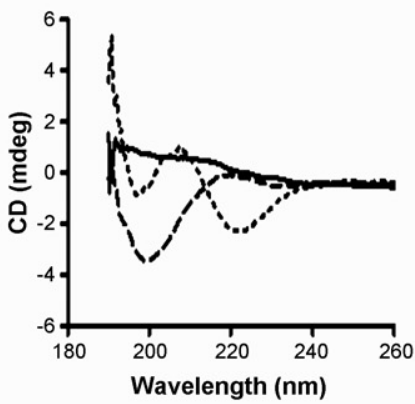

(d) AcHTD-amide

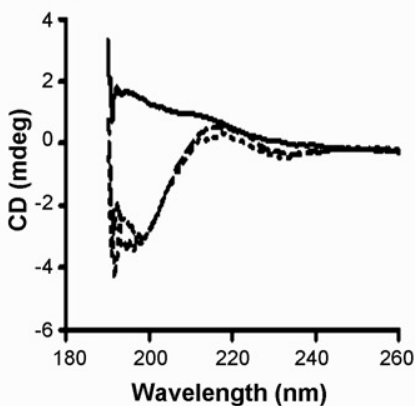

(e)

ARSE-NH

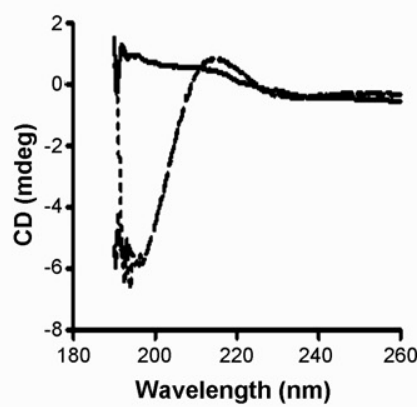

GHSEamide

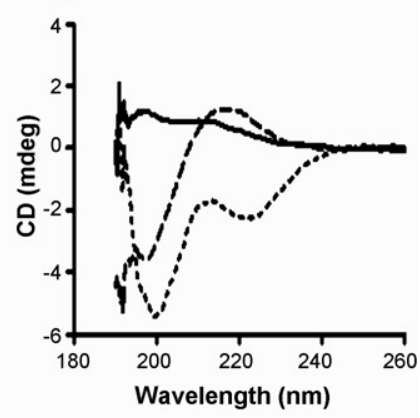

(g) 100 uM HTD-NH ${ }_{2}$, pH 7.0

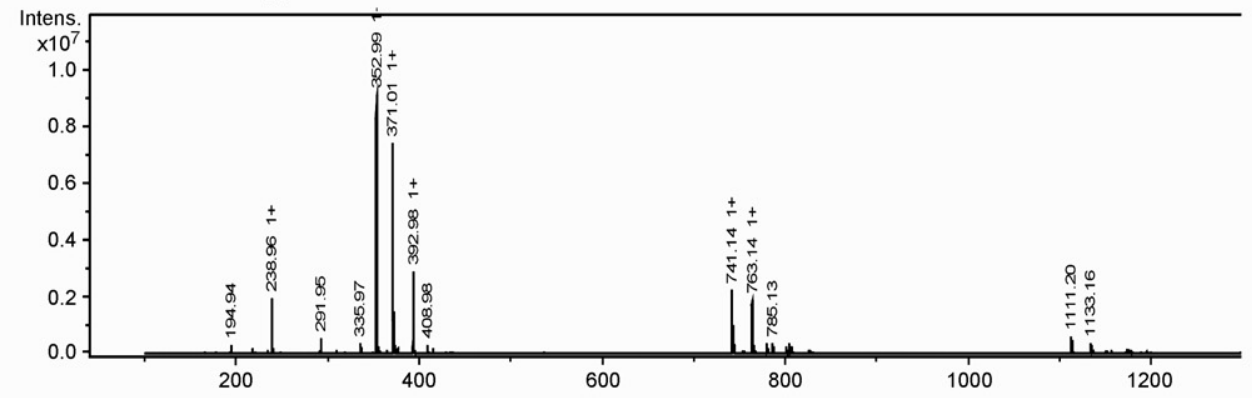

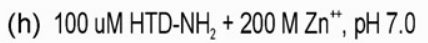

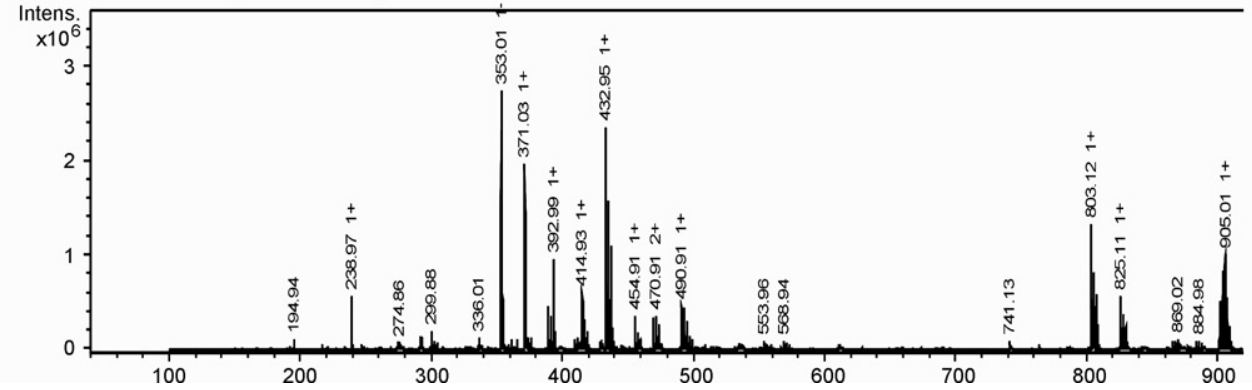

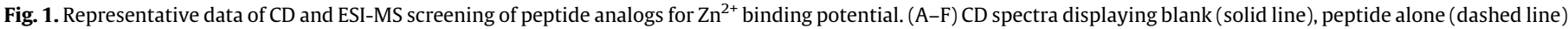

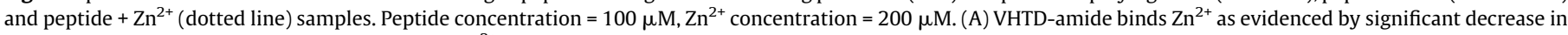

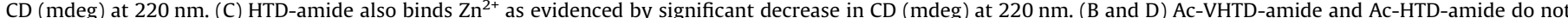

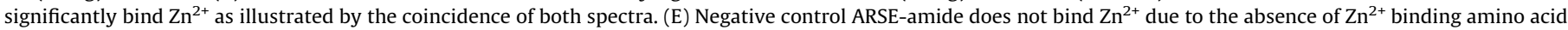

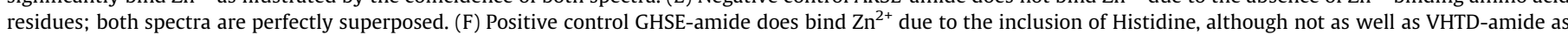

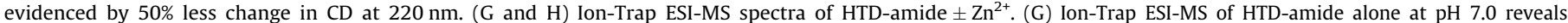
multimerization to dimers, trimers and least stably, tetramers. $(\mathrm{H})$ Conversely, in the presence of $\mathrm{Zn}^{2+}, 1: 1$ and $2: 1 \mathrm{HTD}: \mathrm{Zn}^{2+}$ complexes are readily detectable at pH 7.0.

in the presence of $\mathrm{Zn}^{2+}$ (Fig. 1G). GHSE amide was used as a positive control and was found to form a stable $1: 1 \mathrm{Zn}^{2+}$ adduct but not as efficiently as HTD amide/GHTD amide and VHTD amide (Fig. 1F and Table 1). The $\mathrm{pH}$ dependence of zinc binding was tested using ISF402 at $1 \mathrm{mg} / \mathrm{ml}$ dissolved in deionized water with $\mathrm{pH}$ adjustment using sodium hydroxide and measurement of the change in $C D$ signal at $220 \mathrm{~nm}$ (Table 2). The reduction in the negative peak at $220 \mathrm{~nm}$ was only apparent at pH 6 or higher, which is consistent with the deprotonation of histidine aiding zinc complex formation.

Potentiometric titration of HTD amide was performed to determine the stoichiometry of $\mathrm{Zn}^{2+}$ binding (Fig. 2). Addition of $\mathrm{Zn}^{2+}$ to give a 1:1 HTD:Zn ratio produced a profound shift in the titration curve which is consistent with strong binding. The 
Table 1

Circular dichroism and Electro-Spray Ionization Mass Spectrometry screening of peptide analogs for $\mathrm{Zn}^{2+}$ binding potential.

\begin{tabular}{|c|c|c|c|c|}
\hline Peptide & $\begin{array}{l}\Delta \mathrm{CD} \\
220 \mathrm{~nm}\end{array}$ & ESI-MS M* & Multimers & $\begin{array}{l}\mathrm{Zn}^{2+} \text { complex } \\
\left(\text { peptide }{ }_{n}: \mathrm{Zn}^{2+}{ }_{n} \text { ) }\right.\end{array}$ \\
\hline HTD-amide & ++ & 371.20 & $n=1>2>3>4$ & $1: 1>2: 1(++)$ \\
\hline GHTD-amide & ++ & 428.19 & $n=1>2$ & $1: 1>2: 1(++)$ \\
\hline VHTD-amide & ++ & 471.21 & $n=1>2$ & $1: 1>2: 1(++)$ \\
\hline Ac-HTD-amide & - & 413.18 & $n=1$ & $1: 1(+)$ \\
\hline Ac-VHTD-amide & - & 512.25 & $n=1$ & $1: 1(+)$ \\
\hline VHTD-OH & ++ & 471.21 & $n=1>2$ & $1: 1>2: 1(++)$ \\
\hline VHT-amide & ++ & 355.21 & $n=1$ & $1: 1(+)$ \\
\hline DTHV-amide & + & 470.23 & $n=1$ & $1: 1>2: 1(+)$ \\
\hline VVTD-amide & - & 432.24 & $n=1>2$ & - \\
\hline VHTN-amide & ++ & 469.24 & $n=1$ & $1: 1(++)$ \\
\hline VHAD-amide & ++ & 440.22 & $n=1>2$ & $1: 1>2: 1(++)$ \\
\hline ARSE-amide & - & 461.25 & $n=1>2$ & - \\
\hline GHSE-amide & ++ & 428.18 & $n=1$ & $1: 1(++)$ \\
\hline
\end{tabular}

For description of $\mathrm{CD}++,+,-=$ marked ( $>2 \mathrm{mdeg}$ ), significant $(<2 \mathrm{mdeg}$ ) and absent $\triangle \mathrm{CD}$, respectively. Similarly, when describing ESI-MS++,,$+-=$ marked $\left(\mathrm{Zn}^{2+}\right.$ adduct $>20 \% \mathrm{M}^{*}$ ), significant $\left(\mathrm{Zn}^{2+}\right.$ adduct $<20 \% \mathrm{M}^{*}$ ), and absent (no $\mathrm{Zn}^{2+}$ adducts observed) zinc binding peak intensities, respectively. The series of multimers from monomer to tetramer are represented by $n=1, \ldots, 4$.

Table 2

The effect of $\mathrm{pH}$ on ISF402/zinc interactions.

\begin{tabular}{lll}
\hline $\mathrm{pH}$ & $\begin{array}{l}\mathrm{CD} \text { signal }([\mathrm{mdeg}]) \text { at } \\
220 \mathrm{~nm} \text { in the } \\
\text { absence of } \mathrm{Zn}^{2+}\end{array}$ & $\begin{array}{l}\text { CD signal ([mdeg]) at } \\
220 \mathrm{~nm} \text { in the presence } \\
\text { of } 2 \mathrm{mM} \mathrm{Zn}^{2+}\end{array}$ \\
\hline 3 & -2 & -2 \\
4 & 0 & 0 \\
5 & 5 & 1 \\
6 & 5 & -13 \\
7 & 0 & -25
\end{tabular}

magnitude of this shift was essentially halved for solution with a 2:1 HTD: $\mathrm{Zn}$ ratio and thereafter, further decreases in $\mathrm{Zn}^{2+}$ concentration induced little change in the titration profile of HTD. This verifies the findings of Ion Trap ESI MS that the predominant HTD:Zn complex has a stoichiometry of $1: 1$.

The interaction between the peptides and zinc was concentra tion dependent as shown by the magnitude of the change in $\mathrm{CD}$ at $220 \mathrm{~nm}$ with increasing $\mathrm{Zn}^{2+}$ concentration (Fig. 3A). This allowed determination of the equilibrium dissociation constant $\left(K_{\mathrm{D}}\right)$ for binding of HTD amide to $\mathrm{Zn}^{2+}$ from the increase in ellipticity as a function of increasing $\mathrm{Zn}^{2+}$. From the saturation binding curve and

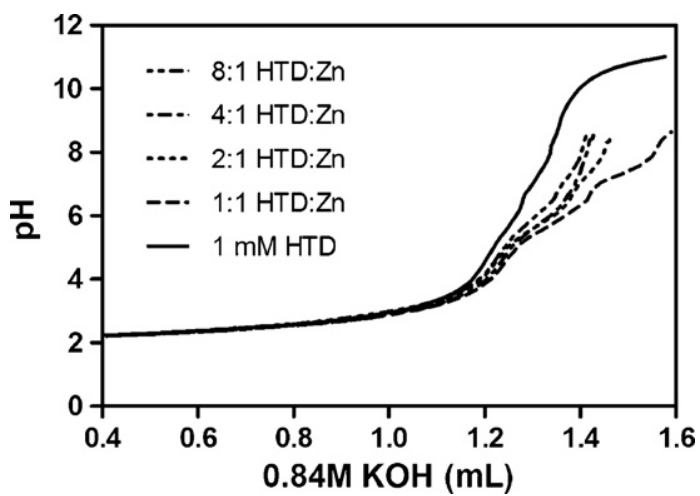

Fig. 2. Potentiometric titration of HTD-amide for determination of zinc binding stoichiometry. Titration of HTD-amide alone and in the presence of decreasing amounts of $\mathrm{Zn}^{2+}$ verifies the findings of Ion-Trap ESI-MS. The 1:1 HTD:Zn reaction leads to a profound shift in the titration curve which indicates strong binding. The magnitude of this shift is essentially halved for $2: 1 \mathrm{HTD}: \mathrm{Zn}$. Thereafter, further decreases in $\left[\mathrm{Zn}^{2+}\right]$ induces only minor changes in the titration profile of HTD. The titration curves for HTD:Zn mixtures terminate at $\mathrm{pH} 8.5$ due to the formation of insoluble zinc hydroxides at higher pHs.
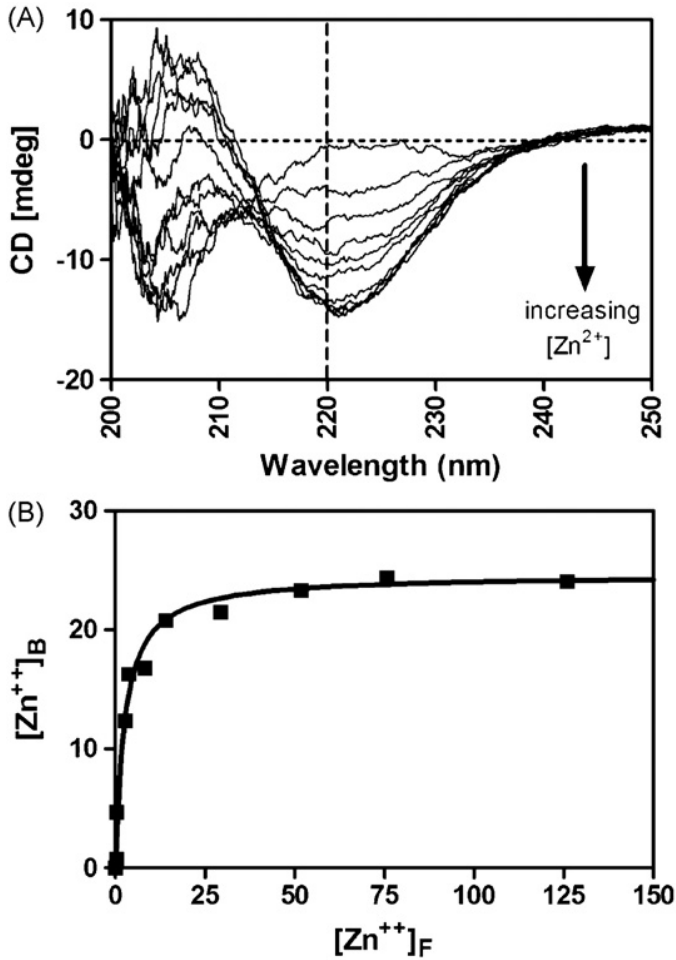

Fig. 3. Representative determination of equilibrium dissociation constant $\left(K_{\mathrm{D}}\right)$ for binding of HTD-amide to $\mathrm{Zn}^{2+}$. (A) Figure showing the increase in ellipticity of $25 \mu \mathrm{M}$ HTD-amide as a function of increasing $\mathrm{Zn}^{2+}$ concentration (path-length $(\mathrm{I})=10 \mathrm{~mm}$ ). The $\mathrm{CD}$ values for each spectra are measured at $220 \mathrm{~nm}$ and used to construct a saturation binding curve. (B) The saturation binding curve was constructed and analyzed as described in experimental procedures. An excellent fit to the data was obtained assuming a 1:1 peptide: $\mathrm{Zn}$ binding model (shown by the solid line). $K_{\mathrm{D}}$ was determined to be $2.3 \pm 0.3 \mu \mathrm{M}$.

assuming a $1: 1$ stoichiometry (Fig. $3 \mathrm{~A}$ ) the $K_{\mathrm{D}}$ was determined to be $2.3 \pm 0.3 \mu \mathrm{M}$ at $\mathrm{pH} 7.4$ in water. Similar analysis performed for GHTD amide and ISF402 revealed $K_{\mathrm{D}} \mathrm{S}$ of $15.9 \pm 4.3$ and $42.9 \pm 13.1$, respectively.

\subsection{Dispersal of insulin hexamers by ISF402}

Insulin forms hexameric complexes that are stabilized by zinc ions and these complexes can be dispersed by zinc binding agents.

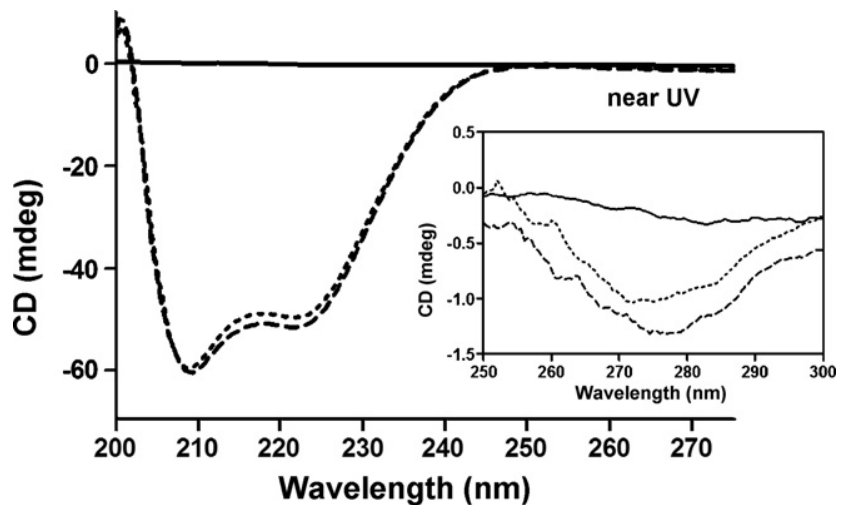

Fig. 4. Near- and far-UV CD spectra of humalin ( $2 Z n$-insulin) and the effect of HTD. Solid line $(-)=$ blank, dashed line $(--)=100 \mu \mathrm{M} 2 \mathrm{Zn}$-insulin, dotted line $(\ldots)=100 \mu \mathrm{M} 2 \mathrm{Zn}$-insulin $+66 \mu \mathrm{M}$ HTD-amide. The main figure illustrates the decrease in ellipticity in the far-UV that accompanies conversion of the hexamer to dimer/monomer due to the addition of HTD-amide, namely; decreases in ellipticity at 217 and $222 \mathrm{~nm}$. The near-UV spectra (inset) reflects the same phenomenon; reduction in ellipticity at $275 \mathrm{~nm}$ and conversion of the hexamer to dimer/ monomer due to the addition of HTD-amide. 
The ability of GHTD amide and ISF402 to disperse hexameric insulin was examined by $\mathrm{CD}$ and size exclusion chromatography.

Hexamer to dimer transitions of insulin can be studied using near and far UV circular dichroism [15]. Fig. 4 illustrates the decrease in ellipticity in the far UV that accompanies conversion of the insulin hexamer to dimer/monomer due to the addition of HTD amide. Characteristic decreases in ellipticity were apparent at both 217 and $222 \mathrm{~nm}$. The near UV spectra (Fig. 4, inset) reflect the same phenomenon with a reduction in ellipticity at $275 \mathrm{~nm}$.

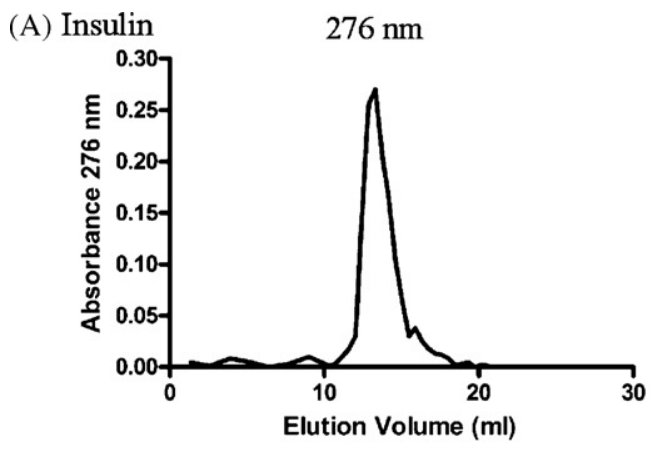

(B) Insulin $+\mathrm{NCP}$

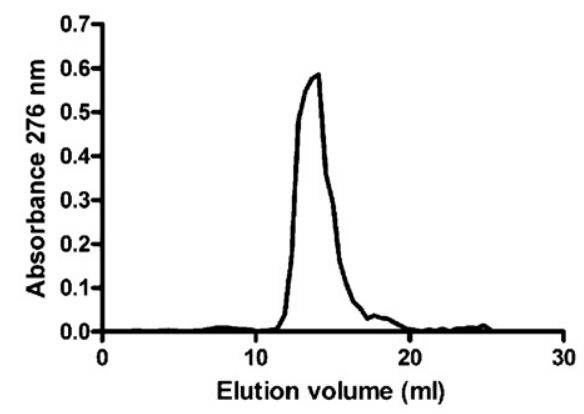

(C) Insulin+GHTDamide

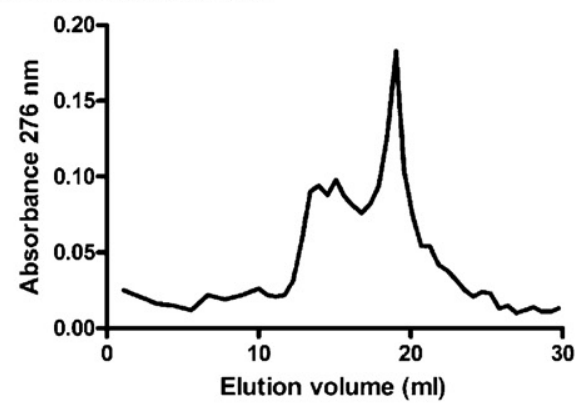

(D) Insulin+ISF402

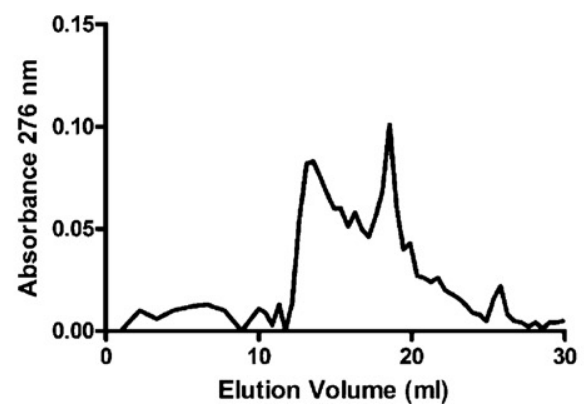

GHTD amide caused similar changes in ellipticity of hexameric insulin solutions (data not shown).

For size exclusion chromatography, the concentration of human insulin was maintained at $1 \mathrm{mg} / \mathrm{ml}(\mathrm{pH} \mathrm{7.4})$ as at this concentration insulin exists predominantly as $\mathrm{Zn}^{2+}$ dependent hexamers. Mon itoring of the eluate at $276 \mathrm{~nm}$ detected an absorbance due to a tyrosyl group which was attributable to insulin, whereas both insulin and the peptides are detected at $214 \mathrm{~nm}$. Human insulin alone eluted as hexameric insulin with a single peak at $13.32 \mathrm{ml}$ (Fig. 5A).
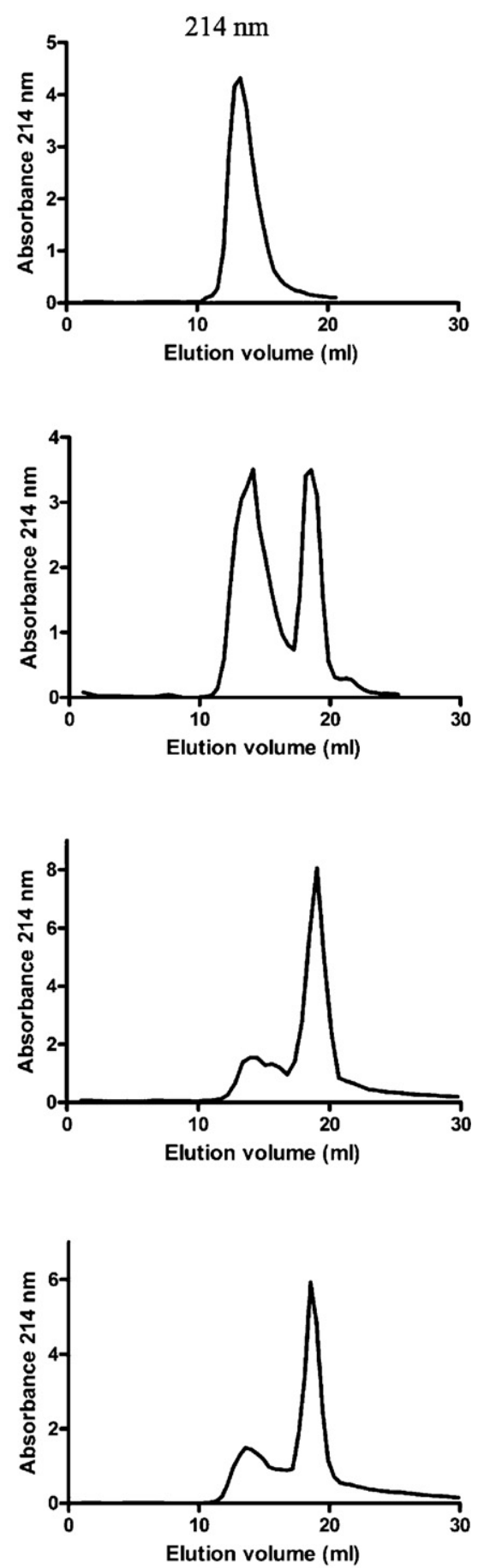

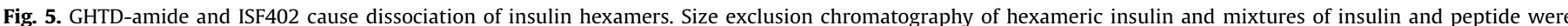

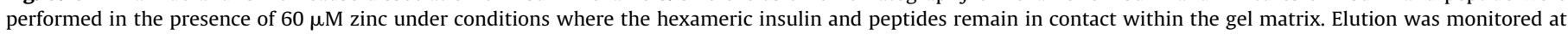

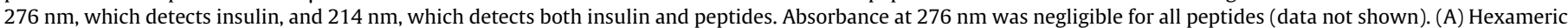

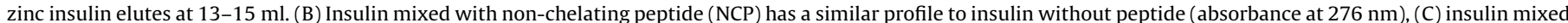

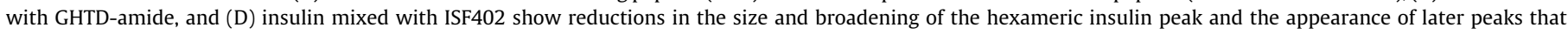
correspond to dimeric and monomeric insulin (E). 
Monitoring of the elution of insulin and a control non chelating peptide (NCP) at $276 \mathrm{~nm}$ (Fig. 5C) shows that the peak at 13.21 $14.09 \mathrm{ml}$ consists of hexameric insulin and there is no dimeric or monomeric insulin present. Monitoring at $214 \mathrm{~nm}$ (Fig. 5B, right panel) showed the hexameric insulin peak and the non chelating peptide which eluted at $1820 \mathrm{~min}$. These results were confirmed by measurement of protein concentration by the Bradford method (data not shown). In the presence of GHTD amide the amount of hexameric insulin was reduced as shown by the reduction and broadening of the peak at $13.3913 .95 \mathrm{ml}$ (Fig. 5C). A minor peak appeared at $15.09 \mathrm{ml}$ and a major peak at $19.05 \mathrm{ml}$, which correspond to dimeric insulin ( $11.8 \mathrm{kDa})$ and monomeric (5.8 kDa) insulin, respectively (Fig. 5C). Monomeric insulin co eluted with the GHTD amide and the magnitude of the hexameric insulin peak detected at $214 \mathrm{~nm}$ was also reduced (Fig. 3C, right panel). Similar results were observed for ISF402 (Fig. 5D).

\subsection{Potentiation of insulin activity by GHTD amide and ISF402}

Insulin potentiation by GHTD amide and ISF402 was tested in Zucker $\mathrm{fa} / \mathrm{fa}$ rats using intravenous insulin tolerance testing. Insulin resistance in the Zucker $f a / f a$ rats was apparent from the small reduction in blood glucose after injection of $1 \mathrm{U} / \mathrm{kg}$ of hexameric zinc insulin (Fig. 6A). Injection of insulin mixed with either GHTD amide or ISF402 at a dose of $1.5 \mathrm{mg} / \mathrm{kg}$ significantly decreased blood glucose in comparison to injection of hexameric zinc insulin alone (Fig. 6A and B). ISF402 was more potent than GHTD amide in that it caused a greater reduction in the AUC for the glucose concentration time course $(p<0.005$, Fig. 6B). Serum insulin concentrations were higher $10 \mathrm{~min}$ after injection of insulin/peptide mixtures compared to insulin injected controls (Fig. 6C). This was most pronounced for ISF402 where insulin

(A)

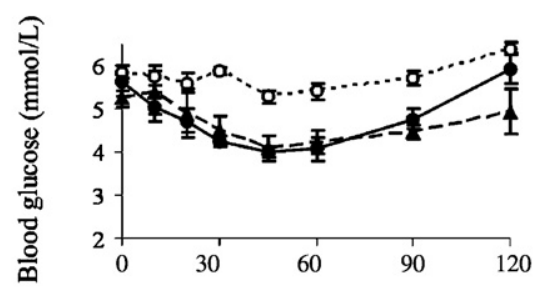

(C)

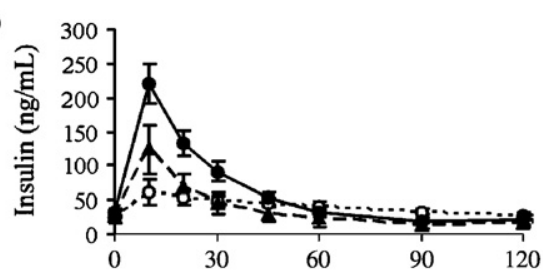

(E)

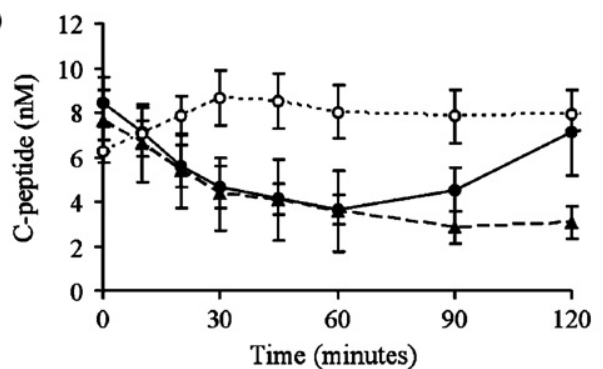

concentrations 10 min after injection were 10 fold higher than after injection of insulin alone. The peak of serum insulin was attributable to the injected insulin since $C$ peptide levels were decreased by each of the insulin/peptide mixtures (Fig. 6E). In contrast, there was a moderate increase in serum $C$ peptide after injection of insulin alone.

\subsection{Insulin potentiation with monomeric lispro insulin}

Lispro insulin, which does not form zinc stabilized hexamers, was used to test whether insulin potentiation by ISF402 was related to zinc chelation and dispersal of insulin hexamers. Lispro insulin or hexameric bovine insulin and $1.5 \mathrm{mg} / \mathrm{kg}$ ISF402 were injected intravenously into Zucker $f a / f a$ rats and insulin sensitive Sprague Dawley rats. For Zucker $f a / f a$ rats the insulins were used at $1 \mathrm{U} / \mathrm{kg}$ body weight whereas for Sprague Dawley rats, which are not insulin resistant, the amount of insulin injected was reduced to $0.5 \mathrm{U} / \mathrm{kg}$ in order to minimize hypoglycemia. The area under the curve (AUC) for the blood glucose time profiles over 60 min were calculated (Fig. 7A). Blood glucose time profiles are shown in Figs. 7B and C. In Zucker rats each of the treatments (ISF402 + hexameric insulin, lispro, and ISF402 + lispro) signifi cantly reduced blood glucose compared to hexameric insulin alone and the combination of lispro with ISF402 had the greatest glucose lowering effect (Fig. 7A). In Sprague Dawley rats, all treatments significantly reduced blood glucose but there was no additive effect of ISF402 and lispro insulin apparent. The blood glucose time profiles for hexameric insulin with ISF402 and lispro insulin both with and without ISF402 were all similar with maximum reductions in blood glucose occurring more rapidly in Sprague Dawley rats (by 15 min after injection) than in Zucker rats (Fig. 7C).
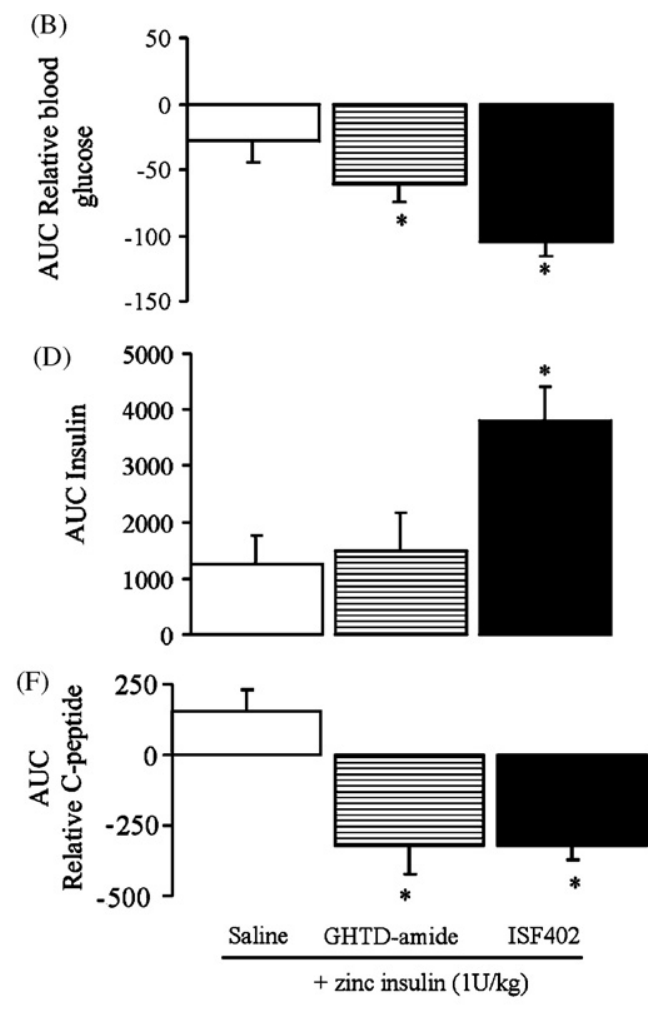

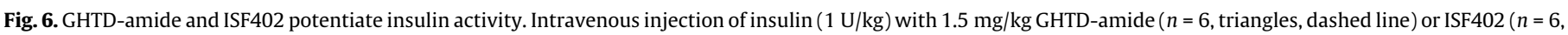

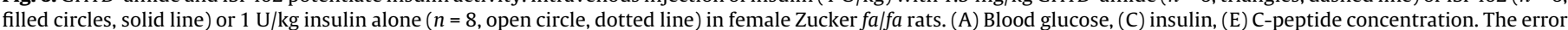

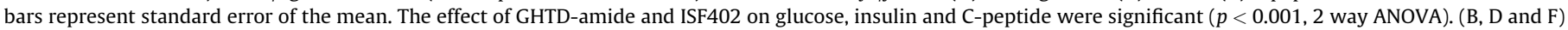

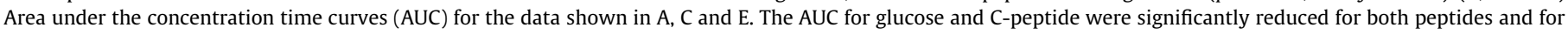
ISF402 the AUC insulin was significantly increased compared to control ( ${ }^{*} p<0.01$, Student's $t$-test). 

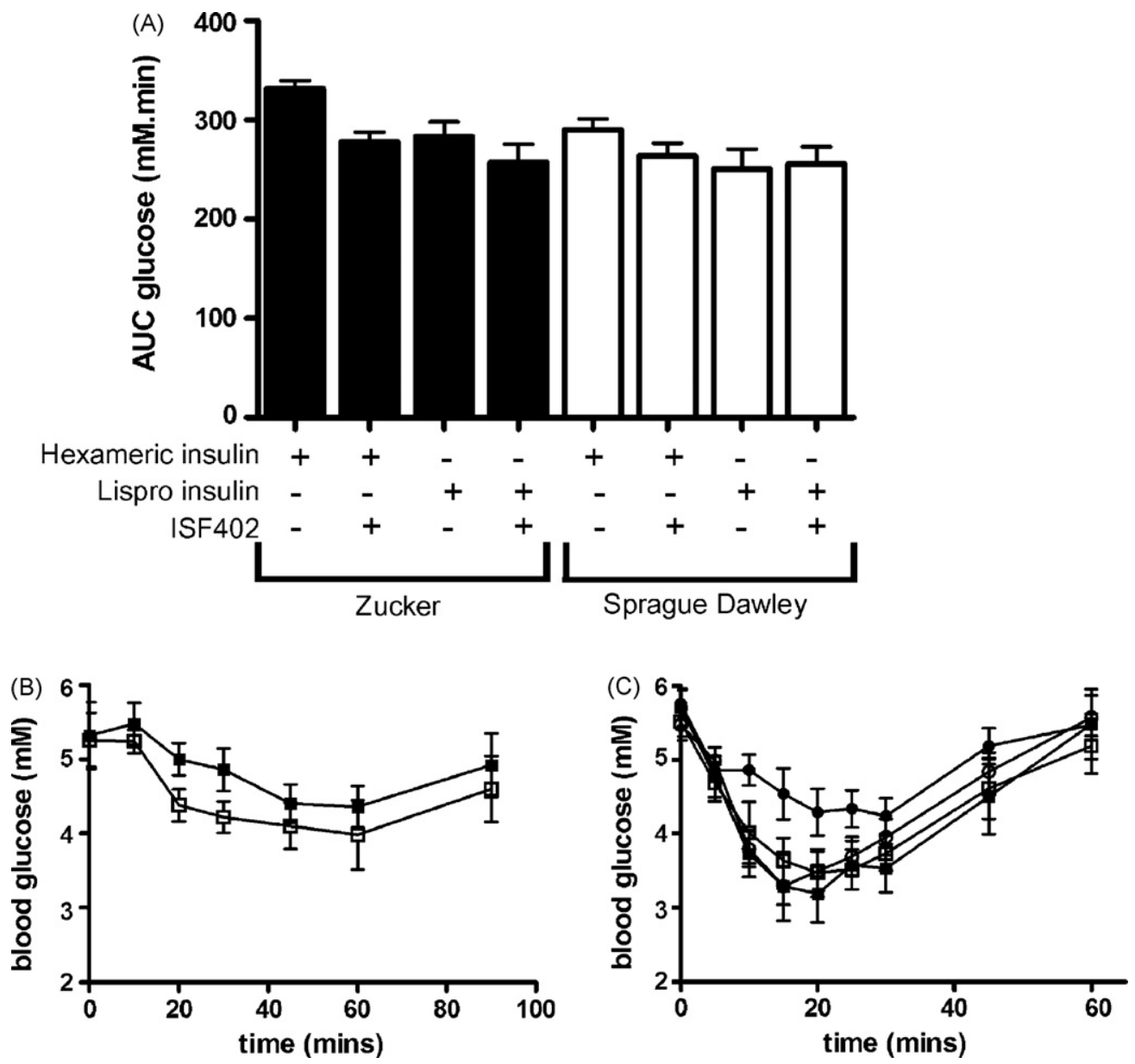

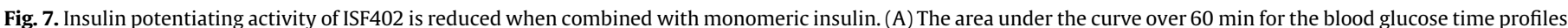

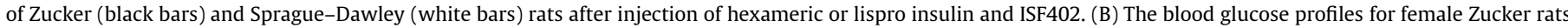

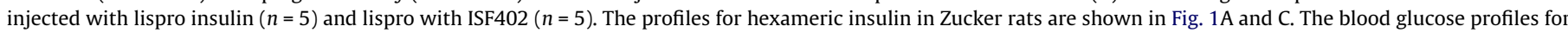

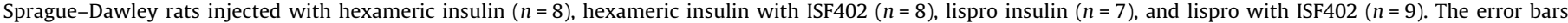
represent standard error of the mean.

\section{Discussion}

GHTD amide was originally purified from human urine as a peptide with insulin potentiating activity $[17,18]$. Here we show, using a variety of in vitro and in vivo systems, that GHTD amide, HTD amide and an analog VHTD amide (ISF402) are zinc chelating peptides that influence the oligomeric state of insulin in vitro, and that ISF402 enhances insulin mediated blood glucose reductions in insulin resistant rats, and that at least part of the insulin potentiation attributable to the tetrapeptides may be explained by accelerated dispersal of insulin hexamers.

GHTD amide and ISF402 are likely to be zinc binding peptides since they contain histidine, which is often involved in co ordinating $\mathrm{Zn}^{2+}$, and aspartic acid, which can also contribute to zinc binding [24]. Generally, tetrapeptides lack secondary structure due to their small size, but interactions with zinc can induce conformational changes [10]. The CD profile of GHTD amide and ISF402 in the presence of zinc was very similar to that previously described for short alpha helices in peptides [4]. The presence of histidine and an adjacent free $\alpha$ amino group were found to be the primary determinants of zinc binding and the change in ellipticity at $220 \mathrm{~nm}$ for these peptides was concentration dependent. Estimation of dissociation constants was $2.28 \mu \mathrm{M}$ for HTD amide and 15.9 and $42.9 \mu \mathrm{M}$ for the tetrapeptides GHTD amide and
ISF402, respectively. These dissociation constants are close to the free $\mathrm{Zn}^{2+}$ ion concentration normally found in plasma, which is of the order of $1015 \mu \mathrm{M}$ [13], and so may well have physiological relevance.

Insulin hexamer formation proceeds by the combination of three dimers with two zinc ions through interactions with the histidine residues at position 10 of the B chains [9,7]. In vivo, insulin biosynthesis occurs within the beta cells of the pancreas where proinsulin is sequestered within $\mathrm{Zn}^{2+}$ and $\mathrm{Ca}^{2+}$ rich storage/secretory vesicles and assembled into $\mathrm{Zn}^{2+}$ and $\mathrm{Ca}^{2+}$ containing hexamers. Upon acidification of the secretory granule, proinsulin is converted to insulin and $\mathrm{C}$ peptide by proteolytic enzymes and this significantly lowers the solubility of the insulin hexamer, causing crystallization within the vesicle [6]. The propensity for insulin to form stable hexameric complexes with zinc ions has been exploited since the 1930 s to produce slow acting formulations of insulin for treatment of diabetes. More recently, fast acting insulins have been developed by substituting amino acids that co ordinate and stabilize hexameric insulin complexes to produce dimeric/monomeric forms that are more rapidly released from the injection site into the circulation [12]. The dissociation of hexameric zinc insulin into monomers is hypothe sized to be a rate limiting step in the systemic absorption of insulin from a subcutaneous injection site [5] and zinc chelating agents increase the rate of dispersal of hexameric insulin in vitro $[8,11]$. It 
has also been proposed that in vivo an endogenous $\mathrm{Zn}^{2+}$ chelator is required for sufficiently rapid dispersal of hexameric insulin upon release from beta cell secretory granules [8].

In this study we have shown the loss of hexameric and the formation of dimeric and monomeric insulin species when GHTD amide or ISF402 were present but not when a non chelating peptide was used. Dispersal of insulin hexamers by GHTD amide was confirmed by near UV circular dichroism [16]. From these results it can be concluded that GHTD amide and ISF402 are zinc binding peptides that can disperse zinc stabilized hexamers of insulin. This prompted us to explore in vivo the effect of the peptides on insulin mediated glucose disposal.

GHTD amide and ISF402 enhanced reductions in blood glucose levels when combined with insulin and altered the serum insulin time profiles causing a large peak in serum insulin early in the time course that was not apparent in controls. This was not due to stimulation of endogenous insulin secretion as serum $C$ peptide was significantly decreased, which is indicative of reduced pancreatic insulin release.

A relationship between dissolution of hexameric insulin and insulin potentiation was shown using ISF402 and co injection with lispro insulin. In lispro insulin the Pro and Lys at position B28 and B29 are reversed so hindering the formation of dimers, which are an intermediate step in hexamer formation. The monomeric property of lispro insulin in vivo enables its use in the treatment of diabetes as a fast acting insulin analog. While in Zucker rats there were some further reductions in blood glucose when ISF402 was combined with lispro, in Sprague Dawley rats co injection of ISF402 with lispro insulin did not cause further reductions in blood glucose concentrations. This data is consistent with ISF402 interacting with injected hexameric insulin to promote the formation of monomeric insulin. We propose a model for the action of HTD amide peptides in which the zinc ion is chelated from the exposed core of the zinc insulin hexamer causing its destabilization and rapid dispersal to monomers. When ISF402 is present, the insulin hexamers disperse so that the insulin monomers are free to bind to receptors, however, when lispro insulin is used in place of hexameric zinc insulin this effect is not observed as lispro insulin is already in monomeric form. Notably, injection of $1 \mathrm{U} /$ $\mathrm{kg}$ body weight of lispro insulin alone caused a greater reduction in blood glucose and $C$ peptide concentration than did $1 \mathrm{U} / \mathrm{kg}$ body weight of hexameric insulin, consistent with the notion that monomeric insulin acts more rapidly than hexameric insulin after intravenous injection. A similar function for $\mathrm{C}$ peptide in disaggregating hexameric complexes of insulin at the site of subcutaneous injection has previously been proposed [22]. Implicit in our findings is that insulin hexamers take some minutes to disperse upon dilution in blood. Testing this directly would require direct measurement of the behavior of insulin oligomers in blood, which is limited by the complexity of blood as a matrix and its incompatibility with available technology for determining oligomeric states of insulin. Regardless, the presence of endogenous GHTD amide in pancreatic beta cells [19] and its ability to chelate $\mathrm{Zn}^{2+}$ and disperse hexamers of insulin as demonstrated here make GHTD amide a candidate for the endogenous chelator that is hypothesized to ensure rapid dispersal of beta cell hexameric insulin upon release into the circulation [8].

Our previous studies have shown that GHTD amide potently stimulates glycogen synthesis in cultured liver and muscle cell lines, and that this activity was not dependent on the addition of insulin to the culture media [19]. Hence GHTD amide appears to have two activities that promote glucose disposal, rapid dispersal of hexamers of insulin through zinc chelation and a direct stimulation of glucose disposal through stimulation of glycogen synthesis. The greater reduction in glucose in Zucker rats injected with ISF402 and lispro insulin compared to injection of insulin alone may be due to this insulin independent stimulation of glycogen synthesis.

In conclusion, we have shown that GHTD amide and ISF402 are zinc binding peptides that disperse hexameric insulin in vitro and that in vivo enhancement of insulin activity is reduced or absent when monomeric lispro insulin is used. These results suggest that dispersal of zinc stabilized insulin hexamers accounts in part for the insulin potentiating activity of these peptides. GHTD amide and ISF402 may prove useful as therapeutic treatments for diabetes by optimizing the activity of injected and endogenous insulin in the insulin resistant state.

\section{Acknowledgments}

We are grateful to Ray Spark and the staff of the Animal Facility of the Department of Biochemistry and Molecular Biology at Monash University, Clayton, Victoria, Australia for their expert technical assistance.

This work was financially supported by Dia B Tech Ltd.

\section{References}

[1] Andrushchenko VV, Vogel HJ, Prenner EJ. Optimization of the hydrochloric acid concentration used for trifluoracetate removal from synthetic peptides. J Pept Sci 2007;13:37-43.

[2] Bailyes EM, Guest PC, Hutton JC. Insulin synthesis. In: Ashcroft FM, Ashcroft $\mathrm{SJH}$, editors. Insulin: molecular biology to pathology. NY: Oxford Univ. Press; 1992.

[3] Blundell T, Dodson G, Hodgkin D, Mercola D. Insulin: the structure in the crystal and its reflection in chemistry and biology. Adv Protein Chem 1972;26:279-402.

[4] Chin DH, Woody RW, Rohl CA, Baldwin RL. Circular dichroism spectra of short, fixed-nucleus alanine helices. Proc Natl Acad Sci USA 2002;99:1541621.

[5] Ciszak E, Beals JM, Frank BH, Baker JC, Carter ND, Smith GD. Role of C-terminal B-chain residues in insulin assembly: the structure of hexameric LysB28ProB29-human insulin. Structure 1995;3:615-22.

[6] Coffman FD, Dunn MF. Insulin-metal ion interactions: the binding of divalent cations to insulin hexamers and tetramers and the assembly of insulin hexamers. Biochemistry 1988;27:6179-87.

[7] Dodson G, Steiner D. The role of assembly in insulin's biosynthesis. Curr Opin Struct Biol 1989;8:189-94.

[8] Dunn MF. Zinc-ligand interactions modulate assembly and stability of the insulin hexamer-a review. BioMetals 2005;18:295-303.

[9] Emdin SO, Dodson GG, Cutfield JM, Cutfield SM. Role of zinc in insulin biosynthesis. Some possible zinc-insulin interactions in the pancreatic B-cell. Diabetologia 1980;19:174-82.

[10] Hénin O, Barbier B, Boillot F, Brack A. Zinc-induced conformational transitions of acidic peptides: characterisation by circular dichroism and electrospray mass spectrometry. Chem Eur J 1999;5:218-26.

[11] Hill CP, Dauter Z, Dodson EJ, Dodson GG, Dunn MF. X-ray structure of an unusual $\mathrm{Ca}^{2+}$ site and the roles of $\mathrm{Zn}^{2+}$ and $\mathrm{Ca}^{2+}$ in the assembly, stability, and storage of the insulin hexamer. Biochemistry 1991;30:917-24.

[12] Howey DC, Bowsher RR, Brunelle RL, Woodworth JR. [Lys(I328) Pro(B29)I]human insulin. A rapidly absorbed analogue of human insulin. Diabetes 1994;43:396-402.

[13] King JC, Hambidge KM, Westcott JL, Kern DL, Marshall G. Daily variation in plasma zinc concentrations in women fed meals at six-hour intervals. J Nutr 1994; $124: 508$.

[14] Kuipers BJH, Gruppen H. Prediction of molar extinction coefficients of proteins and peptides using absorption of the constituent amino acids at $214 \mathrm{~nm}$ to enable quantitative RP-HPLC-MS analysis. J Agric Food Chem 2007;55:544551.

[15] Lang CH, Bagby GJ, Hargrove DM, Hyde PM, Spitzer JJ. Alterations in glucose kinetics induced by pentobarbital anesthesia. Am J Physiol 1987;253(6 Pt 1):E657-63.

[16] Liu FY, Kildsig DO, Mitra AK. Insulin aggregation in aqueous media and its effect on alpha-chymotrypsin-mediated proteolytic degradation. Pharm Res $1991 ; 8: 925-9$.

[17] Ng FM, Zimmet P, Bornstein J, Malinek M, Taft P. Isolation and characterization of a hypoglycaemic peptide from human urine. Proc Endocr Soc Aus $1971 ; 14: 51$.

[18] Ng FM, Zimmet PZ, Seiler G, Taft P, Bornstein J. Insulin potentiating action of a peptide fraction from urine. Diabetes 1974;23:950-6. 
[19] Paule SG, Nikolovski B, Gray RE, Ludeman JP, Freemantle A, Spark RA, et al. GHTD-amide: a naturally occurring beta cell-derived peptide with hypoglycemic activity. Peptides 2008. doi: 10.1016/j.peptides.2008.12.022.

[20] Rahuel-Clermont S, French CA, Chou CI, Kaarsholm NC, Dunn MF. Mechanisms of stabilization of the insulin hexamer through allosteric ligand interactions. Biochemistry 1997;36:5837-45.

[21] Roy M, Brader ML, Lee RW-K, Kaarsholm NC, Hansen J, Dunn MF. Spectroscopic signatures of the $\mathrm{T}$ to $\mathrm{R}$ conformational transition in the insulin hexamer. J Biol Chem 1989;264:19081-5.
[22] Shafqat J, Melles E, Sigmundsson K, Johansson B-L, Ekberg K, Alvelius G et al. Proinsulin C-peptide elicits disaggregation of insulin resulting in enhanced physiological insulin effects. Cell Mol Life Sci 2006;63: $1805-11$.

[23] Steiner DF, Peterson JD, Tager HS, Emdin S, Ostberg Y, Falkmer S. Comparative aspects of proinsulin and insulin structure and biosynthesis. Am Zool 1973;13:591-604.

[24] Thickman KR, Davis A, Berg JM. Site selection in tandem arrays of metalbinding domains. Inorg Chem 2004;43:7897-901. 